\title{
4500 Gram Ve Üstü Fetusların Maternal Ve Fetal Sonuçları: Tek Merkez Deneyimi
}

\author{
Maternal And Fetal Outcomes Of Fetuses With 4500 Grams And Over: Single Center Experiement
}

\section{Evrim Bostancı ERGEN ${ }^{1}$}

1. Zeynep Kamil Research Hospital,Department of Obstetrics and Gynecology, Istanbul, Türkiye

\section{$\ddot{O Z Z T T}$}

Amaç: Bu çalışma, hastanemizde doğan makrozomik fetuslar ile ilişkili fetal ve maternal sonuçları irdelemeyi amaçlamaktadir.

Gereçler ve Yöntem: Çalı̧̧mada retrospektif olarak Ă̆ustos 2013-Ekim 2017 tarihleri arasında Zeynep Kamil Kadin ve Çocuk Hastalıkları Eğitim ve Araştırma Hastanesinde doğan 4500 $g$ ve üstü bebek doğurmuş (Grup 1) 243 hasta ile 3500-4500 g bebek doğurmuş 378 hasta (Grup 2) dahil edildi.

Bulgular: Ortalama yas $30.97 \pm 6.24$, ortalama gebelik saylst $2.28 \pm 1.24$ olarak hesaplandl. Ortalama gebelik haftast ise $39.46 \pm 1.30$ olarak bulundu. Gruplar arasinda gebelik saylsi ve gebelik haftası açısından anlamlı farklılık saptanmazken; anne yaş ortalaması $(p<0.05)$, postpartum kanama $(p<0.01)$ ve postterm oraninda $(p<0.01)$. istatistiksel olarak anlaml bir fark saptandi. Yenidoğan 1. ve 5. dk. APGAR skoru $<7$ olan olgu orant, erkek bebek saylsi ve YDYB gereksinimi açısından da Grup 1 lehine anlamlı bir fark vardl $(p<0.05)$.

Sonuç: Fetal makrozomi yüksek mortalite ve morbidite ile ilişkilidir. Doğum şekline titizlikle karar verilmelidir.

Anahtar Kelimeler: makrozomi, sezaryen, postpartum atoni

\section{ABSTRACT}

Objective: This study aims to investigate the fetal and maternal outcomes associated with macrosomic fetuses in our hospital.

Material and Methods: Two hundred forty three fetuses (Group 1) with 4500 grams and above and 378 fetuses (Group 2) with 3500-4500 grams who were born in Zeynep Kamil Women's and Children's Hospital of Education and Research Hospital between August 2013 and October 2017 were included in this retrospective study.

Results: The mean age was $30.97 \pm 6.24$ and the mean parity was $2.28 \pm 1.24$. The mean gestational week was $39.46 \pm 1.30$. There was no significant difference between the groups in terms of number of pregnancies and gestational week $(p<0.05)$. There was statistically significant difference between the groups in terms of postpartum hemorrhage $(p<0.01)$ and postterm rate $(p<0.01)$. A significant difference was found in macrosomic group in terms of the number of cases with APGAR score $<7$ at 1 and 5 min, number of male infants and need for neonatal intensive care $(p<0.05)$.

Conclusion: Fetal macrosomia is associated with high mortality and morbidity. The type of delivery should be evaluated carefully.

Keywords: macrosomia, cesarean section, postpartum atony

İetişim Bilgileri

Sorumlu Yazar: Evrim Bostancı ERGEN

Yazışma Adresi: Zeynep Kamil Research Hospital, Dept. of Obstetrics and Gynecology, Üsküdar, İstanbul 34668, Türkiye E-posta: evrimbostanc6666@gmail.com

Tel: +90 (216) 3910680

Makale Geliş Tarihi: 24.12.2017

Makale Kabul Tarihi: 05.02.2018

DOI: http://dx.doi.org/10.16948/zktipb.370505

\section{GİRiş}

American College of Obstetricians and Gynecologists (ACOG) 4500 gram ve üzerindeki bebekleri makrozomi olarak tanımlamaktadır; doğumların \%10 kadarında makrozomi görülür (1). Makrozomik bebekler, anne için; artan sezaryen oranlar1, epizyo oranlar1, derin perine laserasyonu ve artan postpartum kanama oranları gibi riskler taşırken, bebek için; omuz distosisi, klavikula kırığı, brakiyal pleksus hasarı, hipoglisemi ve solunum s1kıntısı gibi riskler taşır(2,3). Fetal ağırlığı etkileyen faktörler; gestasyo $\neg$ nel diyabet, obesite, etnik faktörler, miad aşımı ve yüksek parite olarak sayılabilir $(3,4)$. Bu sonuçlar diyabetik gebe de saptanırken, diyabetik olmayan gebelerde de saptanabilir(4). Kötü maternal ve fetal sonuçlar 4000 gr ve üzerinde artabilirken, 4500 gr ve üstünde net şekilde artmaktadır $(5,6)$. Makrozomik bebeklerde sezaryan oranı \%73.3 gibi artmış oranda saptanır(7).

Çalışmamızda doğumda fetal ağırlığın 4500 gr ve üstünde olmasının, maternal-fetal sonuçlara etkisini araştırmayı amaçladık.

\section{GEREÇ ve YÖNTEM}

Çalışmamızda Ağustos 2013-Ekim 2017 tarihleri arasında Zeynep Kamil Kadın ve Çocuk Hastalıkları Eğitim ve Araştırma Hastanesinde doğum yapan $4500 \mathrm{~g}$ ve üstü bebek doğurmuş (Grup 1) 243 hasta ile $3500-4500$ g bebek doğurmuş 378 hasta (Grup 2) dosyas1 retrospektif olarak incelendi. Bebek doğum ağırlığına göre oluşturulmuş bu iki grup; maternal yaş, gebelik sayısı, gebelik haftası, doğum şekilleri, bebek cinsiyeti, preeklampsi, erken membran rüptürü(EMR) ve preterm gelişimi, , epizyotomi gereksinimi, postpartum hemoraji, 3 . ve 4 . derece perine yırtığ 1 , 1. ve 5. APGAR skoru, doğumda oluşan komplikasyonlar, bebe $\neg$ ğin yenidoğan yoğun bakım(YDYB) gereksinimi açısından karşılaştırıldı.

Çalışmada elde edilen bulgular değerlendirilirken, istatistiksel analizler için IBM SPSS Statistics22.0 programı kullanıldı. Çalışma verileri değerlendirilirken tanımlayıcı istatistiksel metodların (Ortalama, Standart sapma) yanı sira niceliksel verilerin karşılaştırılmasında normal dağılım gösteren parametrelerin iki grup arası karşılaştırmalarında Student $t$ test, normal dağılım göstermeyen parametrelerin iki grup arası karşılaştırmalarında Mann Whitney U test kullanıldı. Niteliksel verilerin karşı- 
laștırılmasında ise Ki-Kare testi, Fisher's Exact test ve Continuity Correction (Yates) test kullanıld1. Anlamlılık $\mathrm{p}<0.05$ düzeyinde değerlendirildi.

\section{BULGULAR}

Çalışmaya alınan 621 gebenin yaşları 14 ile 45 yıl arasında değişmekte olup, ortalamas1 $30.97 \pm 6.24$, ortalama gebelik say1s1 $2.28 \pm 1.24$ olarak hesaplandı. Ortalama gebelik haf $\neg$ tası ise $39.46 \pm 1.30$ olarak bulundu. Doğumların 48.3' si vajinal yolla idi. Geri kalan doğumların $5(\% 0.8)$ tanesi müdahaleli doğum idi. Bunların ikisi 4500 gram üstünde saptanırken, 3'ü kontrol grubunda saptand1. Karşılaştırmada anne gravidası ve gebelik haftası açısından istatistiksel olarak anlamlı bir fark saptanmazken, anne yaş ortalaması açısından Grup 1 lehine anlamlı bir fark vard $1(\mathrm{p}<0.05)$ (Tablo 1).

Maternal ve fetal sonuçlara baktığımızda ise doğum şekli olarak beklendiği gibi sezaryenle doğum oran1, postterm doğum oran1, GDM görülme oran1 açısın $\neg$ dan Grup 1 lehine istatistiksel anlamlı bir fark saptanmasına karşın preterm doğum, pprom ve doğum durumu(canl1-ölü bebek) oran $\neg$ larında gruplar arasında anlamlı bir fark yoktu. Yenidoğan 1. ve 5. dk. APGAR skoru $<7$ olan olgu oran1, erkek bebek sayısı ve YDYB gereksinimi açısından da Grup 1 lehine anlamlı bir fark vardı $(\mathrm{p}<0.05)$. Doğum komplikasyonları değerlendirme $\neg$ sinde 4500 g'1n üzeri olgularda 8 olguda omuz distosisi oluşurken, bunlardan 1 'inde klavikula kırığı, 1'inde sürrenal hematom ve klavikula kırığı, 1 'inde cilt altı amfizem ve klavikula kırığg, 4'ünde brakiyal pleksus paralizisi saptanmıştır. 4500 gram üstü grupta 1 olgu sezaryen sonrası vajinal doğum yapt1, maternal ve fetal komplikasyon saptanmadi. Ayrica Grup 1 de sezaryen olan hastaların 20'sinde takiplerinde yara yeri enfeksiyonu saptand1. Postpartum hemoraji açısından da Grup 1 lehine istatistiksel olarak anlamlı bir fark vardı.

\section{TARTIŞMA}

4500 gr ve üstü olarak değerlendirilen fetusların doğum yönetimi, doğum şekli, postpartum takibi, artan kötü maternal ve fetal sonuçlar nedeniyle dikkatli yapılmalıdır. Çalışmamızda özellikle erkek fetuslarda, 4500 gr ve üstü bebek ağırlığı oranının yüksek olduğunu, sezaryen ile doğum yapılsa bile gestasyonel diyabet olsun yada olmasin 4500 gr ve üstü bebeklerin YDYB gereksiniminin arttığını ve Apgar skorlarının düşük olduğunu, 4500 gr ve üstü fetusların sezaryeni sonrası yara enfeksiyonunun daha s1k görüldügünü saptadık.

Çalışmamıza benzer şekilde; Ju et al. yaptığı çalışmada 40 haftanın üzerindeki gebeliklerde makrozominin 4 kat daha fazla olduğunu göstermiştir(6). 4500 gram ve üstü gebeliklerin \%31.3' ünü postterm olarak saptadık ve bu olguların 4'ünde omuz distosisi yaşand1. Postterm gebelik, muhtemelen ileri gebelik haftasının yüksek doğum ağırlığıyla ilişkisi nedeniyle omuz distosisi için bir risk faktörüdür (8). Norveç'te yapılan çalışmada; $\operatorname{miad}(\mathrm{n}=379,445)$ ve miad aşımı $(n=65,796)$ doğumlar karşılaştırılmış, postterm doğumlarda omuz distosisi rölatif riskinin \% 30 arttı̆̆ saptanmıştır(9).

Çalışmamızda 4500 gr ve üstü grupta 8 omuz distosisi saptanırken, 3500-4500 gr grubunda 2 olguda omuz distosisi saptand1. Benzer şekilde yapılan çalişmalarda; doğum ağırlığı 4000 gr ve üzerine çıkt1ğında omuz distosisi görülme sıklığ1 arttığ 1 , doğum ağırlıkları $\geq 4500 \mathrm{~g}$ olduğunda ise omuz distosisine bağlı morbidite ve mortalitenin belirgin şekilde arttığ1 tespit edilmiştir $(10,11)$. Yine başka bir çalışmada omuz distosisi riskinin, doğum ağırlığ $>4500$ gr ve üzerindeyse 7.6 kat arttığ saptanmıştır(12). Yapılan toplum bazlı bir çalışmada; doğum ağırlı̆̆1> $4500 \mathrm{~g}$ olan bebeklerin yüzde 70'inin erkek olduğu, oysa tüm yenidoğanların yüzde 51'i erkek olduğu saptanmış [14], yine aynı şekilde başka bir

Tablo 1: Maternal sonuçların gruplara göre dağılımı.

\begin{tabular}{|c|c|c|c|c|}
\hline & & GRUP 1 & GRUP 2 & \multirow{2}{*}{$\mathrm{p}$} \\
\hline & & Mean $\pm S D$ (median) & Mean $\pm S D$ (median) & \\
\hline Anne Yaşı & & $32.10 \pm 5.72$ & $30.22 \pm 6.45$ & ${ }^{1} 0.001 * *$ \\
\hline Gebelik Haftası & & $39.40 \pm 1.51$ & $39.50 \pm 1.14$ & ${ }^{1} 0.382$ \\
\hline Doğum Sayısı & & $2.34 \pm 1.18(2)$ & $2.25 \pm 1.32(2)$ & ${ }^{2} 0.057$ \\
\hline & & n (\%) & n (\%) & \\
\hline Preeklempsi & & $20(\% 8.2)$ & $10(\% 2,6)$ & ${ }^{3} 0.001^{* *}$ \\
\hline Preterm & & $2(\% 0.8)$ & $1(\% 0.3)$ & ${ }^{4} 0.564$ \\
\hline Postterm & & $76(\% 31.3)$ & $72(\% 19)$ & ${ }^{3} 0.001^{* *}$ \\
\hline Pprom & & $1(\% 0.4)$ & $9(\% 2.4)$ & ${ }^{4} 0.098$ \\
\hline GDM & & $79(\% 32.5)$ & $14(\% 3.7)$ & ${ }^{3} 0.001^{* *}$ \\
\hline Epizyo & & $50(\% 20.6)$ & $251(\% 66.4)$ & ${ }^{3} 0.001^{* *}$ \\
\hline Postpartum Kanama & & $14(\% 5.8)$ & $6(\% 1.6)$ & ${ }^{3} 0.008^{* *}$ \\
\hline Roб̆um Sekli & NSD & $52(\% 21.4)$ & $248(\% 65.6)$ & ${ }^{5} 0.001^{* *}$ \\
\hline & Sectio & $191(\% 78.6)$ & $130(\% 34.4)$ & \\
\hline Rоб̆um Rurumи & Canlı doğum & $240(\% 98.8)$ & 377 (\%99.7) & ${ }^{4} 0.305$ \\
\hline & Ölü doğum & $3(\% 1.2)$ & $1(\% 0.3)$ & \\
\hline
\end{tabular}


Tablo 2: Fetal sonuçların gruplara göre dağılımı.

\begin{tabular}{|c|c|c|c|c|}
\hline & & GRUP 1 & GRUP 2 & $\mathrm{p}$ \\
\hline \multirow[t]{2}{*}{ Apgar 1} & $<7$ & $12(\% 4.9)$ & $1(\% 0.3)$ & ${ }^{3} 0.001 * *$ \\
\hline & $\geq 7$ & 231 (\%95.1) & 377 (\%99.7) & \\
\hline \multirow[t]{3}{*}{ Apgar 5} & $<7$ & 7 (\%2.9) & $1(\% 0.3)$ & ${ }^{3} 0.014 *$ \\
\hline & $\geq 7$ & 236 (\%97.1) & 377 (\%99.7) & \\
\hline & & n (\%) & $\mathrm{n}(\%)$ & \\
\hline YDYBÜ & & $54(\% 22.2)$ & $1(\% 0.3)$ & ${ }^{3} 0.001 * *$ \\
\hline \multirow[t]{2}{*}{ Cinsiyet } & Erkek & 181 (\%74.5) & 247 (\%65.3) & ${ }^{5} 0.016^{*}$ \\
\hline & $\mathrm{KIz}$ & $62(\% 25.5)$ & 131 (\%34.7) & \\
\hline
\end{tabular}

1 Student $t$ test, 2 Mann-Whitney $U$ test, 3 Yates-Continuity Correction test, 4 Fisher's Exact test, 5 Ki-kare test, ${ }^{*} \boldsymbol{p}<0.05,{ }^{* *} \boldsymbol{p}<0.01$

çalışmada makrozominin de erkek be $\neg$ beklerde daha sık görüldüğü bildirilmiştir(13). Bu araştırmalara paralel olarak çalışmamızda 4500 gr ve üstü fetusların \%74.5(n=181)' i, 3500-4500 gr fetuslarm $\% 65.3$ ( $n=247$ )'ü erkek idi. 4500 gr ve üstü fetuslar, yenidoğan hipoglisemisi açısından da risk altındadırlar. Çalışmamızda YDYB gereksinimi artmasının yanında bu durumun hipoglisemi nedenli gerçekleşmesi 4500 gr ve üstü fetuslarda daha siktır. Benzer şekilde Kraiem ve ark. 4000-4500 g grubundaki yenidoğan hipoglisemi riskini \% 2 saptarken, 4500 gr ve üstü grubunda \% 18 saptamışlardır(14). Çalışmamıza benzer şekilde, Gyurkovits ve ark. çalışmalarında Apgar skoru <7 açısından 4000-4449 g ile $>4500 \mathrm{~g}$ olan makrozomik fetusları kendi aralarında karşılaştırdığında anlamlı bir farklılığın olduğunu ortaya koymuşlardır(15).

Çalışmamızda sezaryen doğum oranını 4500 ve üstü olan grupta $\% 78.6$ bulurken, $3550-4500$ gr olan grupta bu oran \%34.4'te kalmıştır. Sezaryen oranlarının yüksek olmasının nedeninin geçi $\neg$ rilmiş uterin cerrahi endikasyonunun da dâhil edilmesi olduğunu düşünüyoruz. Yapılan çalışmalarda da $4500 \mathrm{~g}$ ve üstü fetuslarda; sirasıyla \% 16.7, 36\% ve \% 22.3'lük sezaryen oranları tespit edilmiştir(16,17,18).

Çalışmamızdaki kısıtlamalarımız ise; hastaların vücut kütle indeksi ve kilo alımı ile fetal makrozomi ve gebelik sonuçları ile arasındaki ilişkiyi analiz etmedik. Çünkü makrozomik gebeliklerin nedenlerini değil, sonuçlarını incelemeyi amaçladık.

Sonuç olarak; çalışmamızda 4500 gr ve üstü fetuslarda sezaryen doğum, erkek fetus, postpartum kanama, omuz distosisi, neonatal hipoglisemi oranlar1nın arttığını ancak epiztotomi oranlarının artmadığ 1 tespit edildi. Gelecekteki araştırmalar, makrozomik fetusların tanısına ve yönetimine 1şık tutacaktır.

\section{KA YNA KLAR}

1- Martin JA, Hamilton BE, Sutton PD, Ventura SJ, Menacker F, Kirmeyer S. Births: final data for 2004. Natl Vital Stat Rep. 2006;55(1):1- 101 .

2- Mehta SH, Sokol RJ. Shoulder dystocia: risk factors, predictability and preventability. Semin Perinatol 2014;38:188- 193.
3- Bamberg C, Hinkson L, Heinrich W. Prenatal detection and consequences of fetal macrosomia. Fetal Diagn Ther 2013;33:143-148.

4- Esakoff TF, Cheng YW, Sparks TN, Caughey AB: The association between birth weight $4000 \mathrm{~g}$ or greater and perinatal outcomes in patients with and without gestational diabetis mellitus. Am J Obstet Gynecol, 2009; 200: 672.e1-4

5- $\quad$ Bjorstad AR, Irgens-Hansen K, Daltveit AK, Irgens LM: Macrosomia: mode of delivery and pregnancy outcome. Acta Obstet Gynecol Scand, 2010; 89: 664-69

6- $\quad J u$ H, Chadha Y, Donovan T, O’Rourke P: Fetal macrosomia and preg $\neg$ nancy outcomes. Aust N Z Obstet Gynaecol, 2009; 49: 5049 .

7- $\quad$ Sinclair BA, Rowan JA, Hainsworth OT. Macrosomic infants are not all equal. Aust N Z J Obstet Gynaecol 2007; 47: 101-5.

8- $\quad$ Acker DB, Sachs BP, Friedman EA. Risk factors for shoulder dystocia. Obstet Gynecol 1985; 66:762.

9- Campbell MK, Ostbye T, Irgens LM. Post-term birth: risk factors and outcomes in a 10-year cohort of Norwegian births. Obstet Gynecol 1997; 89:543

10- Boulet SL, Alexander GR, Salihu HM, Pass M. Macrosomic births in the united states: determinants, outcomes, and proposed grades of risk. Am J Obstet Gynecol 2003; 188:1372.

11-Zhang X, Decker A, Platt RW, Kramer MS. How big is too big? The perinatal consequences of fetal macrosomia. Am J Obstet Gynecol 2008; 198:517.e1.

12-Weissmann Brenner A, Simchen M J, Zilberberg E, Kalter A, Weisz $B$, Achiron R, Dulitzky M. Maternal and neonatal outcomes of macrosomic pregnancies. Med Sci Monit. 2012;18(9):PH77-81.

13-Donma M. Macrosomia, top of the iceberg: The charm of underlying factors. Pediatrics International 2011; 53: 78-84.

14-Kraïem J, Chiha N, Bouden S et al: The delivery of macrosomic infants weighing $4500 \mathrm{~g}$ and more. A report of 61 cases. Tunis Med, 2004; 82(7): 656-61

15-Gyurkovits Z, Kálló K, Bakki J, Katona M, Bitó T, Pál A, Orvos H. Neonatal outcome of macrosomic bebeks: an analysis of a two-year period. Eur J Obstet Gynecol Reprod Biol 2011;159(2):289-92.

16-Berard J, Dufour P, Vinatier D et al: Fetal macrosomia: risk factors and outcome. A study of the outcome concerning 100 cases $>4500 \mathrm{~g}$. Eur J Obstet Gynecol Reprod Biol, 1998; 77: 51-59

17-Raio L, Ghezzi F, Di Naro E et al: Perinatal outcome of fetuses with a birth weight greater than $4500 \mathrm{~g}$ : an analysis of 3356 cases. Eur J Obstet Gynecol Reprod Biol, 2003; 109(2): 160-65

18-Navti OB, Ndumbe FM, Konje JC: The peri-partum management of pregnancies with macrosomic babies weighing $>$ or $=4,500 \mathrm{~g}$ at a tertiary University Hospital. J Obstet Gynaecol, 2007; 27(3): 267-70. 